\title{
Narrative as a learning tool in science centers: potentials, possibilities and merits
}

\section{Mai Murmann and Lucy Avraamidou}

\begin{abstract}
In this theoretical paper we explore the use of narrative as a learning tool in informal science settings. Specifically, the purpose of this paper is to explore how narrative can be applied to exhibits in the context of science centers to scaffold visitors science learning. In exploring this idea, we analyze the theoretical, structural and epistemological properties of narrative. In the pages that follow, we first discuss the advantages and possibilities for learning that science centers offer alongside challenges and limitations. Next, we discuss the role of narrative in science, as a tool for supporting science learning. We then continue with an analysis of the structural and epistemological properties of narrative and discuss how those can serve to establish narrative as a learning tool.
\end{abstract}

KEYWORDS: Science centers and museums, Science comunication:theories and models

\section{Introduction}

During the past few years there has been increasing interest in learning that takes place within informal environments, in educational research $[1,6,14,40]$. The term 'informal learning environments' is often used to describe learning environments outside the traditional area of schools [13]. Given Dierking et al.'s [13] view that learning occurs from various experiences and is an organic, dynamic, never-ending, and holistic phenomenon of constructing personal meaning, then teaching in environments outside schools can create opportunities for students to get involved in activities where learning will be guided by their own interests and needs [42]. In 1999, the American National Association for Research in Science Teaching (NARST) formed an Ad Hoc Committee in Informal Learning with the charge to clarify what constitutes informal learning [42]. Some of the characteristics of out-of-school learning, according to Rennie et al. [42], included the following: (a) it occurs out of school, is self-motivated and guided by learners' need and interests; (b) it is strongly socio-culturally mediated; and, (c) it is a cumulative process involving connections and reinforcement between the variety of learning experiences a person encounters in life (p. 13). Roberts [57] summarized thinking about the meaning of education in museums in three domains: entertainment, empowerment, experience, and ethics:

- Entertainment refers to museum practices and visitor experiences that fall outside such traditional goals as cognitive engagement and information transfer. 
- Empowerment refers to the authorization of alternative modes of knowing and speaking besides the information-based methods traditionally employed in museums.

- Experience refers to new ways of thinking about the basis of knowledge.

- Ethics refers to the value and belief systems that stand behind different criteria for meaning (pp. 131-132).

These domains have been explored in research on museum learning in the past decades with an emphasis on the role of exhibits on learning, with the use of various models and theoretical frameworks. Falk and Dierking [16] proposed the Contextual Model of learning as a framework for studying the complexities of learning within free-choice settings. Drawn upon constructivist, cognitive and sociocultural theories of learning, this model exemplifies the contextually driven processes of interactions between a person's personal, sociocultural and physical contexts. The personal context represents an individual's personal history (e.g., prior knowledge and experiences), the sociocultural context refers to that museum learning is socioculturally situated given than individuals are defined by their social relationships and culture, and the physical context refers to the museum space and its characteristics. Several researchers in the past two decades have studied these contexts and how those impact museum learning.

As Martin [31] described, studies of museum learning research mostly look at exhibitrelated experiences and points to the importance of:

- Structuring scientific knowledge: individuals can be shown to make conceptual gains from museum visits.

- The role of social interaction: family members engage in a variety of strategies that encourage explanation and understanding.

- Mediating experiences and devices: students' class visits to museums can relate to the depth and retention of visit content.

- Institutional meaning: individual's identity as a learner is shaped by the cultural institutions they come in contact with as well as by day-to-day moments in life. (S73-74)

There exists a large number of studies, dated back in 1970s-80s, that focus on cognitive aspects of learning with the use of quantitative research methods in the context of $\mathrm{Mu}-$ seums (e.g., [26, 54]. In the past decade, there has been a shift to the use of qualitative research methods and examination of the social and affective domains of learning in museum settings and other out-of-school settings (e.g., [4, 40, 48, 55, 56]). The findings of these studies provide compelling evidence about the significant role of museums and out-of-school settings on supporting learning and development.

In a study with a random sample of 217 adult visitors to a life science exhibition at a major science center, Falk and Storksdieck [17] found that prior knowledge, interest, motivation, choice and control, within and between group social interaction, orientation, advanced organizers, architecture, and exhibition design affect visitor learning. Likewise, 
reporting on the findings of a three-year study with a random sample of adult visitors to a large recently opened, hands-on, interactive science center, Falk and Storksdieck [17] collected information on why people visited, what they did within the science center, what they knew about the subject presented upon entering and exiting, and what each individual's long-term self-perceptions of their own learning was. The findings of their study showed that all visitors to science centers learned some science, but their identity-related leisure motivations (i.e., personal interests, prior experiences) influenced the nature of their free-choice science learning. Another set of studies has explored how exhibition characteristics or design features impact visitor learning (e.g., [5, 7, 45]). The findings of these studies suggest that interactivity promotes engagement with an exhibit and supports understanding. Such opportunities for interactions, we suggest in this paper, are offered through narrative-based exhibits where a story targets and enforces the strengths and characteristics of informal settings, such as science centers.

\section{Science centers as learning spaces}

The history of science centers goes back in 1969 when the first American science center - The Exploratorium - opened. The science center originated as a result of the Sputnik-shock, and given the subsequent space race between the Soviet Union and the United States which created a need to strengthen the understanding of Science and Technology in the American population. In the following years, many other science centers operated across the U.S.A. . and a new paradigm in the organisation of museum exhibits was developed [37]. The purpose of the development of science centers was to create hands-on exhibits in which visitors could explore freely and construct their own understandings about various scientific phenomena. The goal of the science centers was to show to the public "the wonders of science" by presenting a "forest of scientific phenomena" for visitors to interact with [35] and eventually to increase their interest and understanding of science. Usually, visitors are presented with scientific phenomena through exhibits, where they can manipulate, read, push, pull, and in general use their senses [37]. The exhibits in these science centers are designed upon the constructivist theoretical paradigm, where visitors are provided with opportunities to explore interactive exhibits without any structural guidance but their own curiosity [35].

However, 'traditional' science centers face a main challenge: how to engage visitors, especially young students, in meaningful learning activities? Research has shown that it is difficult to keep students focused on the scientific phenomena illustrated by the exhibits [6]. Science centers emphasize a great degree of play, freedom, and individual choice that seems to conflict with a high degree of cognitive engagement with exhibit content. The physical environment is flooded with competing stimuli that distract students and prevent them from focusing on the learning objectives and in contrast to the formal environment of the school, students must make their own choices in these informal environments for learning [7]. As a result, students often run from one exhibit to the next doing random button pressing, and the average holding time is often less than thirty 
seconds [36]. However, as Allen [5] argued,

It is possible to create exhibit environments where visitors are simultaneously in a constant state of free choice and in the process of learning some form of science. But it is difficult, and calls for a program of research that focuses on the detailed features of the physical environment in which such learning is deeply situated. (p. S18)

Such programs are associated with the goals of school field-trips to science centers to engage students in minds-on, rather than in hands-on only activities. Hence, the challenge becomes one of supporting young students' interaction with an exhibition through meaningful reflection during engagement with hands-on activities [25]. In this paper, we consider three factors that influence how students interact with exhibitions. First of all, the idea of making an open environment for exploration of science seems to contradict students' interest in the exhibition content. The lack of structure in science center exhibitions inhibits cognitive engagement, as visitors feels overwhelmed, disorientated, and insufficient [25]. Second, "the novelty-effect" of unfamiliar settings is considered as having impact on the behavior and learning of students. Studies have shown that students in new settings tend to focus on orienting themselves with space and navigating the exhibitions rather than giving focus to learning conceptual material [16]. Third, the lack of reflection in the way students interact with exhibits is to a large degree dependent on lack of preparation at school prior to the visit. Research on field trips to informal institutions has identified how students' reflections upon exhibition content changes depending on the nature of the activities planned by the teacher, and the mediation of these activities during the visit [49]. What becomes clear in the above is that there exists a need for strategies and tools that support science learning in science centers. One such tool, we suggest in this paper, is narrative. In the next section we offer a definition of narrative alongside a description of its epistemological and structural characteristics as well as its grammar.

\section{Defining narrative}

The term narrative has been used for a number of purposes in the context of various disciplines and hence, a wide range of definitions of this term exist [3]. For general purposes in semiotics and literary theory, a narrative is a story or part of a story [43]. A narrative may be spoken, written, or imagined, and it can be viewed from one or even several perspectives. The American dictionary of English language defines narrative as "a constructive format that describes a sequence of fictional or non-fictional events" [38]. In this paper we view narrative from two perspectives: the story as a designed, fictive, literary tool, and the story as an epistemological tool for learning. The first perspective is connected to the design of a strong and convincing story that scaffolds students. From this perspective structures must be crafted in a way that makes sense to students and interact with other educational elements from the learning activity [4]. The second perspective is connected to the story as a cognitive tool that could scaffold student science learning. Ideally, we argue, these two levels should complement each other. The idea of using narrative to 
scaffold student learning at science centers is related to its sociocultural status - as also the nature of informal settings, such as science centers. Narrative is considered our main form of communication and has been studied and represented in a number of disciplines, such as education, sociology, human psychology, philosophy, history, fiction, film, and others [3, 11]. As reported elsewhere, in 1986 Bruner defined two primary means of thought: paradigmatic and narrative [4]. The paradigmatic mode is in its nature logic, scientific, and is based on reasoning. The narrative mode is sequential, action-oriented, detail-driven, and is influenced by feelings and emotions. According to Bruner [10] the narrative mode is the default mode of thinking. In our everyday lives this is how we organize our thoughts. We discuss previous events to understand ourselves and to plan for the future - we schedule appointments, we dream, and we make promises. We listen to stories throughout our lives and learn how to index them according to themes, topics, goals, protagonists, and actions [27].

\section{The epistemological characteristics of narrative}

Narrative has specific epistemological characteristics, which make it an empowering cognitive tool, or a tool for constructing and communicating meaning [3, 34]. We create and communicate stories about our days, and essentially our lives. When we create a story, we make interpretations of our experiences and of our surroundings in order to organize them in a meaningful way. Horsdal [23] defined this process as 'the explanation-value of the story'. Due to these attributes, we constantly use narrative as means of communication and explanation. We use narrative to organize events by telling about them, by keeping track of the knowledge, by verbally recreating the process we went through to get the knowledge, and by using it in a social way to tell others about our life and experiences $[3,32]$.

Bruner [10] argued that as human beings we are born with certain mental schemas, and that we apply those schemas to stories. Specifically, we use these schemas in order to help ourselves to organize our experiences and as something we can rely on whenever we need to. He claimed that stories are organized representations of human experiences that cool down the chaos that arises when actions, emotions and thinking are mixed together [58]. According to Bruner, stories accomplish this by creating an action that implements problem, temporality, and solution. When we tell a story, we create beginnings and endings in order to ensure coherence, and we make selections and create hierarchies in order to make a sequence. Stories support us when we try to remember the past and when we seek to figure out where to go in the future [10]. Bruner [58] argued that narratives are more than just a means of communication. He claimed that we live in narratives and how we experience the world is constructed in narrative. As he stated, "We live in a sea of stories, and like the fish who will be the last to discover water (according to the proverb), we have our own difficulties grasping what it is like to swim in stories." (p. 147). 


\section{The structural characteristics of narrative}

Several researchers have explored the connection between narrative and human cognition, and argued that the strengths of narrative as a cognitive tool are found in their compository structures $[10,30,39]$. According to these researchers, narratives are not simply accounts created for specific occasions. Instead, stories follow a number of universally structured principles [58]. Mandler [59] proposed that story structures and epistemological properties of narratives are intertwined through a kind of narrative evolution. The certain 'traits' and components of stories are very recognizable to people, presumably because they existed long before people invented writing. Mandler and Johnson [30] suggested that the structures and forms of fairy tales, folktales, fables, and myths have been advanced through generations of traditional storytelling. Since people could not write down their stories, those structures that were the easiest to remember survived. Today, the stories we tell are perfectly aligned with the way we think and understand our world, and because of their familiarity they carry certain expectations for temporality and causal relations [30].

Several researchers have tried to identify the necessary components and structures for narrative $[3,11,34,51]$ In making a point of reference in this paper, we use Avraamidou and Osborne's [3] conceptualization of narrative as composed by the following components:

- Purpose: to help us understand the natural and human world. In the case of the natural world, narratives help the reader to invent new entities, concepts and some picture of the scientist's vision of the material world

- Events: a chain or sequence of events that are connected to each other

- Structure: an identifiable structure (beginning, middle, end) where events are related temporally

- Time: narratives concern the past

- Agency: actors or entities cause and experience events. Actors may either be human or material entities who act on each other

- Narrator: the teller who is either a real character or alternatively, a sense of a narrator

- Reader: the reader must interpret or recognize the text as a narrative (p. 1693)

Each of these components plays a special part in the narrative. The narrative has a purpose, to help us understand the world and help the reader to invent new entities and concepts of the narrated world. It is also characterized by having a chain or sequence of events that are connected to each other and arranged into an identifiable structure, such as beginning, middle, and end, where events are related temporally. By doing this, narratives also establish a sense of time that integrate past and future. The agents (human and nonhuman ones) cause and experience events and give a sense of agency that moves the story forward. Avraamidou and Osborne [3] also emphasized the narrator and the reader as important components of narrative. These can be more or less directly included in the narrative. The narrator can be either a real character or, alternatively, a sense of 
a narrator. The reader can be directed in the text or must at least interpret the text as narrative. Avraamidou and Osborne argued that these important features of narratives are normally not accentuated in traditional expository texts in science education, such as causality, intentionality, and temporality. According to these researchers the purpose of narratives is not merely to help us understand the human world but also to understand the natural world. Science is essentially about developing causal explanations of the material world and these causes can be accentuated by the use of narrative components $[3,34]$. This is aligned with one of the main goals of science centers: to communicate science to the public.

\section{Story grammar: Actantial and Hollywood models}

Our understanding of the narrative components can be enhanced through the concept of story grammar. Mandler [59] and Thorndyke [50] created the Story Grammar [30, 50, 59] to explore why stories provide a means to organize human knowledge. Mandler [59] introduced the concepts of story grammar and story schema. A story schema is a hypothesized mental structure consisting of sets of expectations concerning the way in which stories proceed. According to Mandler [59], humans have mental story schemas in terms of certain expectations to stories because of their specific structures and components. For example, we recognize the structures of fairy tales and folktales. Story grammar, on the other hand, is a rule system devised for the purpose of describing the regularities found in stories. The rules of this system describe the components of which stories are composed and the ordering of these components [59].

Two commonly used models illustrate the concept of story grammar in classic storytelling by organizing the structural components into more superior structures: the Actantial model and the Hollywood model. The Actantial model was developed in 1966 by the semiotican Algirdas Julien Greimas [60]. The model analyzes traditional actions in a story and describes how the agents of the story relate to each other. The model considers four agents: subject, object, helpers, and opponents. If we analyze a traditional story (e.g., fairy tale) by using the Actantial model we recognize a number of agents. In a fairy tale the subject is often the hero of the story who strives for a particular goal, such as freeing a princess or an enchanted animal. However, if the hero could easily achieve this goal, the story would most likely appear as not interesting. Instead, in order to achieve the task, the hero comes across different helpers and opponents, such as evil, lack of knowledge, dragons, good servants, helpful insights, and enchanted swords. The model arranges the agents of the story in relation to each other to make the story interesting and meaningful and it shows the relationship among agents by describing what a subject is striving for, and how the achievement of the goal is influenced by helpers and opponents.

The second classic model of narrative, the Hollywood model complements the Actantial model by outlining the subject's way to the object. This model has its roots in Aristotle's ideas about storytelling [22] and describes the typical phases in traditional storytelling by ensuring a way of building tension as the hero strives for his object. As Bord- 
well, Staiger and Thompson [8] described, this model begins with a prelude that captures the viewer and outlines the general premise of the story to be told. Then a presentation of the agents and an escalation of the conflict follow. When the story reaches its 'point of no return' the entire scenario of the conflict is set and the readers' attention is caught to such a degree that they to get to the end. Then the conflict escalates even further toward the climax of the story in which the hero achieves the goals. Finally, the story fades out in order for the reader to say goodbye [60]. Traditional storytelling often follows the classical story grammar described in the Actantial model and the Hollywood model. These two models act as templates for the design of new stories, thereby using the well-established structures to increase the interest of readers, and their understanding of the story.

\section{Narrative as a learning tool}

The term 'learning tool' describes any device or technique that focuses on students' analytical processes, provides support, and gives directions for the practices of the learners - essentially, it mediates students' understandings of the world [46]. The understanding of narrative as a cognitive tool for learning is based on the assumption that students already know the narrative structure and content and consistently use them in an attempt to understand and retell their experiences [4]. Narrative is a familiar tool given its use for communication in every day life, and which students can use for interpretation [34]. Hence, by introducing narrative to science centers, students have a familiar structure to help them cope with all the unfamiliar elements that comes with learning a new topic, developing skills, and physically navigating in learning environments [4].

The comprehension of how narrative could act as a cognitive tool can be understood within the theory of philosopher Marx Wartofsky [53], who proposed three different levels of tools: primary, secondary, and tertiary ones. According to Wartofsky, primary tools are directly used in production, such as words, texts, and networks. Secondary tools are representations of primary tools, such as recipes, traditional beliefs, and norms. Tertiary tools form a class of tools that Wartofsky called 'Imaginary Worlds'. These tertiary tools are mental representations of the external world. They can affect the way we view the actual world and change the current praxis. These tools are used when we interpret art, in processes of change, and in perception of an environment. Wartofsky's idea of tertiary level tools illustrates how cognitive tools may transform a task in fundamental ways and affect how people engage in the tasks they perform. In this paper, we propose that narrative could be useful in engagement with exhibits in science centers, by acting as tertiary cognitive tools for interpreting the scientific concepts portrayed in exhibits.

\section{The landscape of action}

The assumption that narrative might act as a tertiary tool relates to the structural and emotional properties of stories that encourage people to engage in the story. It relates to an assumption that stories promote motivation and immersion [3]. Bruner [9] argued that 
good stories are not just effective because of their structure but also because they involve the reader emotionally. According to Bruner, stories have two interrelated dimensions. One dimension is the 'landscape of action', which is related to the plot-structure of the story where agents, purposes, events, and time constitute the action of the story. The landscape of action is the primary driver of our curiosity and motivation for reading the story because we meet the story between recognition and identification and difference and uncertainty. Because of its form the story represents something known and familiar; but because we do not know how it will evolve before it is realized, it also represents something unknown [23]. Hence, the story challenges and stimulates readers' curiosity and motivates them to read more and follow along from the very beginning to the very end, which address the challenge of keeping students on task in informal settings, as discussed in the introduction.

\section{The landscape of consciousness}

The second dimension of narrative is called the 'landscape of consciousness'. It outlines the mental state of the characters and how they think or feel [9]. Through the landscape of consciousness readers identify themselves with the story and the characters. In return they get engaged with the story. As Oatley [24] described, when reading and interpreting a story, people feel certain emotions depending on their connection to the characters and their own emotional memories. This emotional engagement in the story may even provide the reader with a sense of being immersed in a story or transported to another time and place. We become absorbed in the narrative universe [9]. According to Green, Brock and Kaufram [20] readers can be so absorbed in the story that they surrender to the story and the cognitive processes step into the background. The reader enters the world of the story as an active character and offers his thoughts and actions as a medium in which the history can be played out. The story becomes a cognitive vehicle that allows us to gain experience in the physical and social environments of the story [25]. Bruner called this "suspension of disbelief" to refer to the temporary acceptance of something incredible or unbelievable that we are willing to accept because we want to make coherence in the story. For example, we are willing to follow Alice into her wonderland and enter the narrative at its premises [23]. Hence, narrative can create motivation and stimulate curiosity by placing us in a zone between known and unknown actions. It may also foster an emotional engagement in the story, at times so strong, that readers are immersed into the universe of the story [3]. When using narrative as a tool for learning we might be able to use these emotional aspects, such as empathy, curiosity, motivation, and immersion to engage students in the learning activity [61]. These features might encourage students to enter the 'imagined world' of narrative in order to organize and interpret activities in the physical world (i.e., engagement with an exhibit). 


\section{The context or physical reality}

As described above, narrative offers an alternative learning context however, students are still situated in the physical reality of a science center. Reiser [41] argued that that even though a scaffold can be a cognitive tool we cannot simply consider it as inside the head of learners. The tool works within a specific system and cannot be considered without exploring other aspects of this system, such as a science center. Also important is what other resources are available to support the tool in terms of teacher support and information resources [46]. Graesser, Olde and Klettke [18] proposed that context and experience matter when interpreting a story whether the narrative is presented in radio, television, film, theater, or literature. They called this 'the situation model'. They based this idea on three theoretical assumptions on how people seek meaning: readers' goals, coherence, and explanation [19]. The first assumption considers the goal of reading a text. A reader interprets a text depending on the purpose of reading the text. It emphasizes that if the goal is learning, the content of the text is read differently than if the goal is purely for entertainment purposes. The second assumption considers how learners create coherence between passages when reading the text. The reader tries to make sense of the text both locally and globally. Local coherence refers to shorter sequences within the narrative, whereas global coherence refers to how narratives constitute a genre similar to what Mandler [59] called story schemas. The last assumption relates to how the reader tries to understand the events in the story through her own experience and theories on psychology and causal effects. This is done in order to explain the intentions of the characters in the story and why things happen. According to these assumptions, readers assign more meaning to the story than the actual content of the story implies. Graesser, Old and Klettke [18] described this as the "mental micro world of what the story is about." The actual outcome is the reader's representation of the world described in the story. The reader's way of understanding the text is thus grounded in the personal and social context of students who use their previous experiences with narratives and learning activities to interpret the story world. Therefore, we ought to consider similar parameters when applying interactive narratives to a learning context, such as a science center. In other words, when considering a narrative as a cognitive tool we ought to assume that students use both the context and their own experiences and emotions to make their own interpretations of the story. In the next section we discuss possible future research directions towards exploring the notion of narrative in science centers.

\section{Future research directions}

Research findings have provided evidence that narrative structures are useful for learning science [4, 47, 62]. Researchers argued that narratives could humanize science education by taking into account the human elements of science and consequently help create a more detailed index than abstract knowledge, usually presented in science education [3, 33, 52]. As Norris, Guilbert, Smith, Hakimelahi and Phillips [34] argued, students find it easier to memorize the familiar cognitive schemas of narrative content and 
form than to memorize traditional discourse genres, such as expository and argumentative texts, where the structure is often unknown. The close correspondence to everyday experience of situations and episodes also make narratives a very natural mechanism of comprehension [18]. Additionally, students benefit from stories in their learning environment because stories provide an opportunity for reflection, evaluation, illustration, exemplification, and inquiry [12] and enhance interest, memory, and understanding [34]. In a review paper about the role of narrative in communicating science, [3] have pointed to the value of narrative in learning and understanding the world we live in and in communicating scientific explanations. In this work, the authors summarized research evidence from studies that provide support to the argument that narrative structures enhance retention and comprehension. Narrative, as suggested in this paper, provides an empowering tool for learning especially within informal settings, given its sociocultural nature and status and that it is used in everyday life interactions and communication [9, 57]. Sociocultural theory has been suggested as an appropriate theoretical framework for museum learning research as it accounts for meanings made within a social context, rather than facts learned [15, 28, 44]. Narrative, as Allen [5] described has been used in exhibits "as an attempt to engage a more diverse audience and to explore different kinds of learning", however, "narratives have less prominent role in science museums, where the dominant mode is still hands-on inquiry with a single-voiced authoritative explanation" (s. 28).

An example of a narrative-based design is offered through the Alexander Fleming Museum in London. The Alexander Fleming museum is a small, three-room museum (i.e., laboratory, video installation, displays with historical information) portraying historical and scientific information about the discovery of penicillin, in a historical narrative format [2]. Another example that illustrates the history of science is the permanent exhibit about human evolution at the Smithsonian National Museum of Natural History in Washington DC. This exhibit asks the question "What does it mean to be human?" This is the first exhibition on human evolution to explore the drama of climate change and the survival challenges it presented to early ancestors. Similarly with the Alexander Fleming Museum, the exhibit is offered in a form of a historical narrative.

In a study which compared the quality of visitors' interaction with a narrative-based exhibit and a reflective-inquiry exhibit, Gutwill-Wise and Allen [21] showed no significant differences. Discussing this finding, the researchers suggested that perhaps the actors (in videos portraying stories) were not skilled enough to make stories truly compelling or perhaps the stories were not very compelling. Contrary to these findings, in a qualitative study examining the impact of a purposefully designed narrative-based exhibit about senses, with seven school classrooms (20-25 students each), from third to sixth grade, we provide evidence of the significant role of stories as learning tools in science centers. For the purpose of this study, we developed a story in the context of which students engaged in conducting an inquiry-based investigation in an exhibit about senses. The context of this narrative-based exhibit is as follows:

In the Senses exhibition, five different activities were designed to demonstrate the classic senses of smell, taste, sight, touch, and hearing, while two other activities 
were designed to demonstrate the more exotic senses of magnetism and thermo reception. Animals were represented in the exhibition as stuffed animals, alive in cages and fish tanks, or through photographs. The story about The Emperor Who Only Believed His Own Eyes was created as a tool to support students' engagement in specially designed activities within the context of the exhibit. The story created a framework for conducting various experiments and completing assignments in preand post-visit activities at school and at the Senses exhibition ([4, p. 5]).

Research data were collected through observations, interviews with teachers and interviews with students. The analysis of these data illustrated that the story structure supported student learning in the following ways: a) motivated students by emphasizing personal relevance and interest; b) it enhanced student ability to reflect upon the scientific concepts communicated through the exhibit; c) it supported students in the process of scientific inquiry; d) it reduced the novelty effect by considering students' prior knowledge; and, e) it oriented students to the science center prior to the visit [4]. Built upon these empirical findings and the need to examine different forms of communicating science in museum settings we propose an examination of the notion of narrative.

In this paper we explored the idea of using narrative as a learning tool in the context of informal science environments, and specifically, in the context of science centers, as a means for addressing certain challenges connected to the unique characteristics of informal settings (e.g., difficulty to keep students engaged for a long time in an exhibit etc). In doing so, we analyzed the theoretical, structural and epistemological properties of stories and discussed how those serve to establish a story as a cognitive tool. As shown in our analysis, by introducing the story-based design into science learning, it may be possible to enhance our understanding of how narrative can engage students in learning activities and essentially support science learning. Given its sociocultural nature and status, narrative holds a great potential for creating motivation, immersion and a sense of agency [3, 4, 34]. With the use of narrative students can create a "landscape of actions" and a "landscape of consciousness" [9] that they carry with them throughout the activity. Moreover, the emotional properties of narrative provide students with a sense of personal meaning about engaging with a learning activity. The narrative provides a feeling of being in charge and being influential, especially when students play a part of the story, which would probably be motivating [4]. In addition, as summarized earlier, students create elaborated mental images of the narrative that seems to create the basis of their understanding of the learning activity. These mental images represent an emotional attachment to their characters, which again creates an emotional goal for solving different assignments.

Even though the argument for the use of narrative as a learning tool in informal settings is compelling, as exemplified in this paper, it raises more questions than answers given that this research area remains largely unexplored. As Allen [5] argued, even though narrative offers a powerful exhibit technique, it has had a less prominent role in science museums. Built upon this view we recommend that future research be directed in this area, and specifically toward responding to the following question: What implications the use of narrative hold for exhibit design? Put differently, how do narrative-exhibits look 
like? What kinds of characteristics do they have? Related questions to answer are ones associated with the ways in which teachers and museum staff use narrative-based design in school field trips, such as: How do teachers use narrative-based materials prior to a field trip? How do museum staff support students' interaction with narrative-based exhibits? Moreover, researchers could explore in further detail the ways in which narrative-based design exhibits support science learning and comprehension and in what ways specific components of narrative support engagement, learning and development within informal science settings. Another interesting research direction would be an exploration of the ways in which narrative can be used to exemplify the nature of science, and the connection of science to history, society and culture. This is in line with the goal of informal education institutions for communicating science to the public and exemplifying the role of science to society.

In closing, this paper makes a contribution to the growing the field of informal science education and science communication to the public, and specifically the use of narrative in communicating science. Existing literature shows that narrative is a compelling tool for learning and fosters a greater motivation for students [3, 4, 34]. Nevertheless, empirical studies that provide concrete evidence of the impact of narrative on student science learning are limited, especially in the context of informal science environments. We hence recommend that future research be directed towards producing a set of studies that explore the use of narrative as a learning tool within the context of informal settings such as museums, science centers, museums, zoos and other out-of-school settings.

\section{References}

[1] P. Aubusson, J. Griffin and M. Kearney (2012), "Learning beyond the classroom: Implications for school science", in B.J. Fraser, K. Tobin and C. McRobbie eds., Second International Handbook of Science Education, Springer, Netherlands, pp. 1123-1134.

[2] L. Avraamidou and J. Osborne (2008), "Science as Narrative: The story of the discovery of penicillin", The Pantaneto Forum (31).

[3] L. Avraamidou and J. Osborne (2009), "The role of narrative in science education", Int. J. Sci. Educ. 31(4): 1-25

[4] M. Murmann and L. Avraamidou (2014), “Animals, Emperors, Senses: Exploring a story-based learning design in a Museum setting” Int. J. Sci. Educ. 4(1): 66-91.

[5] S. Allen (2004), "Design for learning: Studying science museum exhibits that do more than entertain”, Sci. Educ. 88: S17-S33.

[6] P. Bell, B. Lewenstein, A.W. Shouse and M.A. Feder (2009), Learning Science in Informal Environments: People, Places, and Pursuits, The National Academies Press, Washington, DC, U.S.A. .

[7] S. Bitgood and D. Patterson (1995), "Principles of exhibit design", Visitor Behavior 2(1): 4-6.

[8] D. Bordwell, J. Staiger K. and Thompson (1985), Classical Hollywood Cinema: Film style and mode of production to 1960, Routledge, London, U.K. .

[9] J.S. Bruner (1986), Actual minds, possible worlds, Harvard University Press, Cambridge, MA, U.S.A. .

[10] J.S. Bruner (1991), “The narrative construction of reality", Critical Inquiry 18(1): 1-21. 
[11] S. Chatman (1978), Story and discourse: Narrative structure in fiction and film, Cornell University Press, Ithaca, NY, U.S.A. .

[12] C. Conle (2003), "An anatomy of Narrative Curricula", Educational Researcher 32(3): 3-15.

[13] L.D. Dierking, J.H. Falk, L. Rennie, D. Anderson and K. Ellenbogen (2003), "Policy statement of the 'informal science education' ad hoc committee”, J. Res. Sci. Teach. 40(2): 108-111.

[14] J. Dillon (2012), "Science, the environment and education beyond the classroom", in B.J. Fraser, K. Tobin and C. McRobbie eds., Second International Handbook of Science Education, Springer, Netherlands, pp. 1081-1095.

[15] K.M. Ellenbogen, J.J. Luke L.D. and Dierking (2004), "Family learning research in museums: An emerging disciplinary matrix?", Sci. Educ. 88(1): S48-S58.

[16] J.H. Falk and L.D. Dierking (2010), "The 95\% Solution: School is not where most Americans learn most of their science", Am. Sci. 98: 486-493.

[17] J.H. Falk and M. Storksdieck (2010), "Science learning in a leisure setting", J. Res. Sci. Teach. 47(2): 194-212.

[18] A.C. Graesser, B. Olde and B. Klettke (2002), "How does the mind construct and represent stories?”, in M.C. Green, J.J. Strange and T.C. Brock eds., Narrative Impact: Social and Cognitive Foundations, Lawrence Erlbaum Associates, Mahwah, NJ, U.S.A., pp. 231-263.

[19] A.C. Graesser, M. Singer T. and Trabasso (1994), "Constructing inferences during narrative text comprehension", Psychol Rev. 101(3): 371-395.

[20] M.C. Green, T.C., Brock and G.F. Kaufram (2004), "Understanding media enjoyment: The role of transportation into narrative worlds", Commun. Theor. 14(4): 311-327.

[21] J. Gutwill-Wise and S. Allen (2002), "Finding significance: Testing methods for encouraging meaning-making in a science museum", Current Trends in Audience Research and Evaluation 15: $5-11$.

[22] A. Hiltunen (2002), Aristotle in Hollywoood: The anatomy of successful storytelling, Intellect Ltd., Oregon, U.S.A. .

[23] M. Horsdal (2000), Livets fortallinger: en bog om livshistorier og identitet, Borgen, København, Denmark.

[24] K. Oatley (1995), "A taxonomy of the emotions of literary response and a theory of identification in fictional narrative", Poetics 23(1-2): 53-74.

[25] A. Kahr-Højland (2010), Laring er da ingen leg?: En undersøgelse af unges oplevelser $i$ og erfaringer med en mobilfaciliteret fortalling $i$ en naturfaglig kontekst, Southern University of Denmark, Faculty of Humanities, Institut for Litteratur, Kultur og Medier.

[26] J.J. Koran and D.S. Baker (1979), "Evaluating the effectiveness of field experience", in M. Rowe ed., What research says to science teacher 1: 55-67, National Science Teachers Association (NSTA), Washington, DC, U.S.A.

[27] J.L. Lemke (1990), Talking science: Language, learning, and values, Ablex Publishing Corporation, Westport.

[28] G. Leinhardt, K. Crowley and K. Knutson (2002), Learning conversations in Museums, Lawrence Erlbaum Associates, Mahwah, NJ, U.S.A. .

[29] E. Matusov B. and Rogoff (1995), "Evidence of development from people's participation in communities of learners", in J. Falk and L. Dierking eds., Public institutions for personal learning, American Association of Museums, pp. 97-104.

[30] J.M. Mandler and N.S. Johnson (1977), "Remembrance of things parsed: Story structure and recall”, Cognitive Psychol. 9(1): 111-151. 
[31] L. Martin (2004), "An emerging research framework for studying informal learning and schools", Sci. Educ. 88: S71-S82.

[32] P.J. Miller, R. Potts, H. Fung and L. Hoogstra (1990), "Narrative practices and the social construction of self in childhood", Am. Ethnol. 17(2): 292-311.

[33] S.L. Montgomery (1996), The scientific voice, Guilford Press, New York, NY, U.S.A. .

[34] S.P. Norris, S.M. Guilbert, M.L. Smith, S. Hakimelahi and L.M. Phillips (2005), "A theoretical framework for narrative explanation in science", Sci. Educ. 89(4): 535-563.

[35] F. Oppenheimer (1968), “A rationale for a science museum”, Curator: The Museum Journal 11(3): 206-209.

[36] S.G. Paris (1997), "Situated motivation and informal learning", J. Museum Education 22: 22-26.

[37] E. Pedretti (2002), “T. Kuhn Meets T. Rex: Critical Conversations and New Directions in Science Centers and Science Museums", Stud. Sci. Educ. 37(1): 1-41.

[38] J.P. Pickett (2000), The American Heritage dictionary of the English language, Houghton Mifflin, U.S.A. .

[39] D. Polkinghorne (1988), Narrative knowing and the human sciences, State University of New York Press, New York, U.S.A. .

[40] J. Rahm (2010), Science in the making at the margin: A multisited ethnography of learning and becoming in an afterschool program, a garden, and a Math and Science Upward Bound Program, Sense publishers, Netherlands.

[41] B.J. Reiser (2004), "Scaffolding complex learning: The mechanisms of structuring and problematizing student work", J. Learn. Sci. 13(3): 273-304.

[42] L.J. Rennie, E. Feher, L.D. Dierking and J.H. Falk (2003), "Toward an agenda for the advancing research on science learning in out-of-school settings", J. Res. Sci. Teach. 40(2): 112-120.

[43] P. Ricoeur and J.B. Thompson (1981), Hermeneutics and the human sciences: Essays on language, action, and interpretation, Cambridge University Press, Cambridge, U.K. .

[44] L. Schauble, G. Leinhardt and L. Martin (1997), "A framework for organizing a cumulative research agenda in informal learning contexts", J. Museum Education 22(2-3): 3-7.

[45] B. Schneider N. and Cheslock (2003), Measuring results: Gaining insight on behavior change strategies and evaluation methods from environmental education, museum, health and social marketing programs, Coevolution Institute, San Franscisco, CA, U.S.A. .

[46] B. Sherin, B. Reiser and D. Edelson (2004), "Scaffolding Analysis: Extending the Scaffolding Metaphor to Learning Artifacts", J. Learn. Sci. 13(3): 387-421.

[47] M.D. Slater (2002), "Entertainment education and the persuasive impact of narratives", in M.C. Green, J.J Strange and T.C Brock eds., Narrative impact: Social and cognitive foundations, Lawrence Erlbaum Associates, Mahwah, NJ, U.S.A., pp. 157-181

[48] S.M. Stocklmayer, I. Durant and B. Cerini (2011), "Giving mothers a voice: Towards home involved in high school science", Int. J. Sci. Educ. 1(1): 23-46.

[49] H. Sorensen and L.H. Kofod (2004), Experimentarium og skole. Det 7. nordiske forskersymposiet om undervisning i naturfag i skolen. Naturfagenes didaktik - en disiplin i forandring, in E.K. Henriksen and M. Odegaard eds., Høyskolen i Agder, Norwegian Academic Press, Kristianssand, Høyskoleforlaget, Norway.

[50] P.W. Thorndyke (1977), "Cognitive structures in comprehension and memory of narrative discourse", Cognitive psychol. 9(1): 77-110.

[51] M.J. Toolan (2001), Narrative: A critical linguistic introduction, Psychology Press, New York, NY, U.S.A. . 
[52] H.A. Wang and D.D. Marsh (2002), "Science instruction with a humanistic twist: teachers' perception and practice in using the History of Science in their classrooms", Science and Education 11(2): 169-189.

[53] M.W. Wartofsky (1979), Models: Representation and the scientific understanding, Springer, Netherlands.

[54] E. Wright (1980), "Analysis of the effect of a museum experience on the biology achievement of six graders", J. Res. Sci. Teach. 17: 99-104.

[55] H.T. Zimmerman and P. Bell (2013), "Where children see science: Youth's activities as connected to science", Int. J. Sci. Educ. 4(1): 25-53.

[56] H.T. Zimmerman, L.R. McClain and M. Crowl (2013), "Understanding how families use magnifiers during nature center walks", Res. Sci. Educ. 43(5): 1917-1938.

[57] L. Roberts (1997), From Knowledge to Narrative: Educators and the Changing Museum, Smithsonian Institution Press, Washington, DC, U.S.A. .

[58] J.S. Bruner (1996), The culture of education, Harvard University Press, Cambridge, MA, U.S.A. .

[59] J.M. Mandler (1984), Stories, scripts, and scenes: Aspects of schema theory, Erlbaum, Hillsdale, NJ, U.S.A. .

[60] P.H. Larsen (2003), De levende billeders dramaturgi, Lindhardt og Ringhof.

[61] S.P. Norris, S.M. Guilbert, M.L. Smith, S. Hakimelahi and L.M. Phillips (2005), "A theoretical framework for narrative explanation in science", Sci. Educ. 89: 535-563.

[62] E. Klopfer and E. Squire (2008), "Environmental Detectivesthe development of an augmented reality platform for environmental simulations", Educ. Tech. Res. Devel. 56(2): 203-228.

\section{Authors}

Dr. Mai Murmann received her Ph.D. in Science Education from the University of Copenhagen and now works as a researcher/developer at the Experimentarium science center in Copenhagen. Her interests focus on exhibit design and science communication to the public and specifically the use of stories as learning tools. E-mail: maim@experimentarium.dk.

Dr. Lucy Avraamidou is associate professor of science education at the University of Nicosia, Cyprus. She holds a Phd from the Pennsylvania State University and has previously worked as a researcher at the Center for Informal Learning and Schools (CILS). Her work explores issues of teacher learning and development through the construct of teacher identity and examines the use of narrative in science education, with the use of qualitative research methods. E-mail: lucyavraamidou@gmail.com.

How TO CITE: M. Murmann and L. Avraamidou, Narrative as a learning tool in science centers: potentials, possibilities and merits, JCOM 13(02)(2014)A02. 